\title{
Concepções docentes sobre os fatores e processos que envolvem a compreensão leitora
}

\author{
Teachers' conceptions concerning factors and processes involving reading comprehension
}

Concepciones docentes sobre los factores y procesos que envuelven la comprensión lectora

\author{
Terezinha das Graças Laguardia Oliveira ${ }^{1}$ \\ Magaly Quintana Pouzo Minatel ${ }^{1}$ \\ Sandra Regina Kirchner Guimarães ${ }^{1}$ \\ ${ }^{1}$ Universidade Federal do Paraná, Curitiba, PR, Brasil.
}

\begin{abstract}
RESUMO
Foram investigadas as concepções que subjazem as práticas docentes utilizadas para desenvolver a competência leitora, por meio de questionário aplicado a 15 professores ( $4^{\circ}$ ano do Ensino Fundamental), de 10 escolas (Curitiba-PR). Questões com base nas dimensões social, linguística e cognitiva da leitura, e nos fatores necessários à compreensão (texto, leitor e contexto), foram formuladas. As respostas obtidas revelaram pouca clareza quanto aos conteúdos e conceitos relativos à dimensão cognitiva da leitura, o que, em tese, limita a utilização de efetivas propostas de ensino da compreensão leitora. $\mathrm{O}$ relato dos encaminhamentos pedagógicos mostra uma centralidade nas informações explícitas nos textos, indicando fragilidade na promoção de habilidades que podem facilitar a compreensão inferencial e a leitura crítica. Fundamentando-se na análise da operacionalização do ensino da leitura, conclui-se pela necessidade de reformulação das propostas pedagógicas de forma a promover a capacidade de reflexão e de controle deliberado do leitor na construção da sua compreensão.
\end{abstract}

Palavras-chave: Ensino da compreensão leitora. Prática docente. Habilidades linguístico-cognitivas.

\begin{abstract}
Conceptions underlying teaching practices intended to develop reading comprehension were investigated through a questionnaire applied to 15 teachers from the $4^{\text {th }}$ to $9^{\text {th }}$ grade of 10 schools (Curitiba, PR, Brazil). The questions addressed social, linguistic and reading cognitive dimensions and factors necessary to comprehension (text, reader, and context). The answers revealed there is little clarity in regard to content and concepts concerning the cognitive dimension of reading, which, in theory, restricts the use of effective proposals to teach reading comprehension. The reports from teaching referrals show that teachers focus on explicit information provided in texts; that is, skills that facilitate inferential understanding and critical reading are poorly promoted. An analysis of how reading is taught shows a need to reformulate teaching proposals in order to promote in readers the ability to reflect and deliberately construct understanding.
\end{abstract}

Keywords: Teaching reading comprehension. Teaching practice. Linguistic-cognitive skills.

\section{RESUMEN}

Se investigaron las concepciones que subyacen a las prácticas docentes empleadas en la competencia lectora. Se aplicó un cuestionario a 15 profesores (4⿳⺈ año de educación primaria), de 10 escuelas (Curitiba-PR). Las preguntas consideraron las dimensiones social, lingüística y cognitiva de la lectura y factores necesarios para la comprensión (texto, lector y contexto). Las respuestas revelaron poca claridad sobre los contenidos y conceptos relativos a la dimensión cognitiva de la lectura, lo que, teóricamente, limita el uso de efectivas propuestas de enseñanza de comprensión lectora. El relato pedagógico muestra una centralidad en las informaciones explícitas en los textos, indicando fragilidad en la promoción de habilidades que facilitan la comprensión inferencial y la lectura crítica. Basándose en el análisis operacional de la enseñanza de la lectura, se concluye: necesidad de reformulación de las propuestas pedagógicas promoviendo la capacidad de reflexión y control deliberado del lector en la construcción de su comprensión.

Palabras clave: Enseñanza de la comprensión lectora. Práctica docente. Habilidades linguísticocognitivas. 


\section{Introdução}

Por ser atividade complexa, a compreensão na leitura exige habilidades para além da simples decodificação, e isso traz implicações para o ensino escolar. A formação de um leitor para que ele seja competente requer intervenções didático-metodológicas para esse fim, com vistas ao desenvolvimento de habilidades metalinguísticas, imprescindíveis ao bom êxito da proficiência leitora.

Segundo Solé (1998, p.35), o trabalho de compreensão textual frequentemente acontece pela leitura de textos e de respostas a perguntas sobre eles, geralmente referentes a detalhes e aspectos literais. Quem adota essas práticas, conforme a autora, tem a crença de que essas atividades promovem a compreensão leitora, quando, na verdade, relacionam-se à avaliação dessa. Tal procedimento precisa ser reavaliado, pois, mesmo com os avanços científicos na área da linguagem, os brasileiros ainda apresentam níveis de proficiência leitora bem aquém dos considerados adequados, como atesta o Indicador de Alfabetismo Funcional ${ }^{1}$ (Inaf). No ano de 2016, esse indicador reiterou que desde 2011 não se observaram avanços nos níveis de leitura, reafirmando: somente um em cada quatro brasileiros atinge um nível pleno de habilidades no uso da leitura e da escrita (INSTITUTO PAULO MONTENEGRO; AÇÃO EDUCATIVA, 2016, p. 7).

Com o objetivo de identificar aspectos relativos aos conhecimentos dos professores que poderiam interferir no desempenho dos estudantes em termos de compreensão leitora, foi elaborado um questionário intitulado "Apreciação de Professores do Ensino Fundamental sobre os Fatores e Processos Implicados na Compreensão da Leitura", que se respaldou em Viana et al. (2010) e em Spinillo (2013a). Com esse instrumento, averiguou-se como professores de $4 \mathrm{O}$ ano pensam e põem em prática o trabalho com a compreensão leitora.

O questionário compôs-se por quatro blocos de questões, três para se levantar dados sobre os fatores que envolvem a compreensão leitora (o texto, o leitor e o contexto) e um para se conhecer as estratégias de ensino adotadas. As perguntas foram abertas, para que os professores expressassem as suas convicções da maneira mais livre possível, e se pudesse avaliar qualitativamente.

Considerando o perfil dos professores respondentes, constatou-se uma diversidade em termos de idade e de experiência profissional. $\mathrm{Na}$ amostra há professores que estão iniciando a docência e professores, já próximos da aposentadoria, com mais de 25 anos de carreira. Quanto à formação, a maioria tem curso de especialização.

O Indicador de Alfabetismo Funcional (Inaf) é uma pesquisa que avalia habilidades e práticas de leitura, de escrita e de matemática, realizada pelo Instituto Paulo Montenegro em parceria com a ONG Ação Educativa, com o objetivo de mensurar o nível de alfabetismo da população brasileira entre 15 e 64 anos.

\section{Ensino da compreensão leitora: convergências teóricas}

O avanço do estudante na leitura, como em outras aprendizagens, requer do professor a reflexão sobre o que ensinar, como fazê-lo e os objetivos de aprendizagem que se pretende alcançar. Para isso, o docente precisa saber quais conteúdos o estudante necessita aprender e as habilidades linguístico-cognitivas que precisa desenvolver. Para tanto, a compreensão da leitura deve ser trabalhada em todas as áreas do conhecimento, mas, nas aulas de Língua Portuguesa, em função de sua essência, deve ser um dos propósitos centrais de ensino.

A instrumentalização do estudante para a leitura envolve uma série de questões; as habilidades que exige não se desenvolvem, emergem ou evoluem sem o ensino explícito (SILVA; SOUZA, 2016, p. 194). A formação e a experiência são componentes desse conjunto de questões. Quanto mais conhecimento das nuances da leitura, melhor a atuação, pois ensinar a ler requer, segundo Pereira (2015, p.40), considerar o conhecimento, seu aprendizado e ensino. Nesse sentido, a formação pode contribuir muito para um trabalho profícuo com a compreensão leitora.

A leitura, segundo Viana et al. (2010, p. 10), envolve duas grandes instâncias: a das competências simples típica da decodificação, que requer habilidades como de estabelecimento das relações grafema-fonema - e a das competências superiores - que demanda dos leitores habilidades linguístico-cognitivas de ordem sintática, semântica e pragmática, orientando estratégias de compreensão, que facilitam a (re)construção do sentido do texto pelo estabelecimento de relações. O trabalho com essas instâncias deve ser criterioso, haja vista que ambas são necessárias e que, isoladas, não garantem o domínio da leitura. Assim, cabe discutir como ambas podem ser ensinadas e/ou abordadas no contexto escolar.

Morais (2013, p. 74-78) sustenta que não se deve misturar o ensino de tais competências. Segundo ele, essas implicam capacidades distintas, que podem levar o estudante a não se focar em nenhuma das duas propostas. Ademais, a decodificação muito pobre prejudica a compreensão. Alégria, Leybaert e Mousty (1997, p. 110-111) corroboram esse pensamento argumentando, que a associação fonológica, quando não se tem automatismo na leitura, faz o leitor dispensar tanto esforço cognitivo para decifrar as palavras, isto é, para a decodificação, que acaba sobrando muito pouco, ou quase nada, para se investir na compreensão.

Como será discutido, ambas as instâncias são indispensáveis à compreensão textual, por isso se defende que elas precisam ser desenvolvidas paralelamente, mas em momentos diferentes e com estratégias de ensino diferenciadas. Nesse contexto, o professor é essencial. 
É ele quem adapta o conteúdo a ser ensinado, optando por estratégias de ensino, que serão aplicadas aos textos selecionados, o que, conforme Marcuschi (2008), é crucial na motivação do estudante para a leitura.

A escolha de um bom texto faz toda a diferença no ensino da compreensão. Viana et al. (2010) ressaltam que os textos não podem ser tão simples que não acrescentem nada ao leitor, nem tão complexos que o desmotive. Para ela, o importante é avaliar a escolha, conforme as necessidades da Zona de Desenvolvimento Proximal do estudante. Segundo as autoras, há três fatores indispensáveis ao desenvolvimento da leitura proficiente (texto, leitor e contexto), cada um com exigências de conhecimentos para o sucesso na compreensão leitora.

Com relação ao fator texto, é preciso preparar o leitor para operar, de acordo com Viana et al. (2010) e Spinillo (2013a), sobre a estrutura, o conteúdo, a sintaxe e o vocabulário. Em termos estruturais, a unidade temática é construída pela articulação de informações globais (macro), que dizem respeito a todo o contexto; e locais (micro), responsáveis pelas articulações no contexto frasal; esses aspectos, mesmo se não expressos, podem ser inferidos. Isso envolve aspectos como a paragrafação, as concordâncias verbais e nominais, e exige um processo inferencial que proporciona ação interpretativa e reflexiva, capaz de construir conhecimento, ultrapassando os conteúdos do texto. Soares e Emmerick (2013, p. 15) asseveram que a integração desses elementos exige do leitor a elaboração de uma representação mental do texto. Um bom leitor, segundo Oakhill, Cain e Elbro (2017, p.22), constrói imagens globais da significação do texto, evocando-as para transpor a literalidade textual. Com isso, a ampliação das atividades de leitura deve ser gradativa ao longo da escolaridade. Como explica Sousa (2015, p.81), a leitura deve ser entendida como uma ferramenta para aprender. Com o avanço da escolaridade, os textos precisam trazer palavras e ideias novas, para além do conhecimento de mundo da criança, e devem ter extensão adequada. Sobre esse último aspecto, Morais (2013, p. 100-101) considera que, na Língua Portuguesa, é razoável a leitura de 60 palavras por minuto, no $1^{\circ}$ ano, 90 no $2^{\circ}$, chegando a 150 no 5 o ano. Perfetti, Landi e Oakahill (2013) destacam a relevância do vocabulário para a compreensão, pois entender o sentido das palavras é essencial para atribuir significados. Nessa perspectiva, as pesquisas com falantes de inglês, realizadas por Nagy e Scott (2000), chancelam que a compreensão depende da leitura de noventa por cento das palavras de um texto. Pinheiro (2015) categorizou um banco de palavras com incidência em livros didáticos consideradas por ela como sendo de alta, média e baixa frequência. Sousa e Gabriel (2011) corroboram os achados de Pinheiro acrescentando que, o conhecimento insuficiente de palavras de alta frequência, geram dificuldades no estabelecimento de relações de sentido e comprometem a compreensão da leitura.

Além disso, fatores como legibilidade, indicadores tipográficos e outros aspectos editoriais, conforme Viana et al. (2010, p.4), facilitam a compreensão textual, por ajudarem o leitor a se focar em informações importantes. Corroborando essa ideia, Blank (2013, p.2) discorre que a forma de lidar com a informação mudou radicalmente; dos pergaminhos, a sociedade passou a organizar livros e, nestes, os tópicos passaram a separar capítulos e o índice, a levar o leitor direto a um tema específico, sem a necessidade de leitura integral da obra; e, com a chegada dos livros digitais, a estrutura hipertextual se revolucionou: instantaneamente o leitor acessa diferentes tópicos e uma multiplicidade de mídias. Diante desses novos modelos estruturais, a autora propõe a reflexão sobre as concepções de leitura, compreensão e produção textual, já que é inegável que esses recursos tecnológicos modificaram e modificarão ainda mais a experiência com textos (BLANK, 2013, p. 2).

Considerando o fator leitor, a leitura como atividade cognitiva depende do funcionamento das funções cerebrais. Conforme Viana et al. (2010, p. 8), variáveis, como as estruturas cognitivas, afetivas e os processos de leitura ativados pelo leitor, transportam e ativam conhecimentos, interesses e expectativas que acionam estratégias disponíveis. Tais funções permitem operar sobre os conhecimentos de mundo e conhecimentos linguísticos, ativando e realizando processos que facilitam o monitoramento e as inferências.

A dimensão cognitiva da leitura se constrói por meio da memória, do monitoramento e das inferências (SPINILLO, 2013a, p. 178-181). A memória colabora no processamento cognitivo da leitura. Nela, armazenamse os conhecimentos prévios do leitor (linguísticos e de mundo), adquiridos pelas experiências - referências pelas quais o leitor integra e/ou organiza as informações na (re)construção dos sentidos dos textos. Além disso, ela, durante a leitura, promove um processo cognitivo que permite ao leitor reter e integrar informações intratextuais, viabilizando a articulação das ideias. Ressalte-se que a decodificação eficiente - com fluência, velocidade e precisão - deixa a memória de trabalho, ou memória de curto prazo, livre para conduzir o encadeamento entre as proposições e a integração das informações veiculadas (MORAIS, 2013, p.77-78; ALÉGRIA; LEYBAERT; MOUSTY, 1997). Nesse sentido, é correto afirmar que a memória é importante para a compreensão. Segundo Perfetti, Landi e Oakhill (2013, p.252), os leitores que buscam coerência devem ser capazes de monitorar a compreensão, com objetivo de verificar o entendimento e fazer reparos nos trechos em que esse não se mostre razoável. 
Estudos mostram (SPINILLO, 2013b; VIANA et al., 2010) que o monitoramento da leitura leva o leitor a avaliar a sua própria compreensão e a se dar conta de falhas de entendimento (inconsistências internas e externas). Assim, presume-se que o ensino de estratégias de monitoramento contribui para a proficiência em leitura.

A capacidade de inferir é indispensável. Conforme Spinillo (2013b, p. 139), as inferências ocorrem quando o leitor chega a novas proposições, a partir das fornecidas pelo texto e do conhecimento de mundo. Marcurschi (2008, p. 249) expõe que as inferências, na compreensão textual, "são processos cognitivos nos quais os falantes ou ouvintes, partindo da informação textual e considerando o respectivo contexto, constroem uma nova representação semântica". Ressalte-se que a reflexão consciente sobre as inferências e as condições em que elas se dão possibilita "que se avalie o que é feito em termos inferenciais quando compreendemos um texto" (MARCUSCHI, 2008, p. 254). Além disso, permite que o professor auxilie o estudante por meio da metacompreensão, criando propostas pedagógicas que promovem a reflexão sobre a sua capacidade de compreender.

Considerando a escrita como forma de representação oral, há relação entre o desempenho do leitor na oralidade, na leitura e na escrita. Estudos (SPINILLO, 2013b; MARCUSCHI, 2008; KLEIMAN, 2000) mostram que o leitor interpreta conforme a sua bagagem linguística e sociocultural. Com isso, toda proposta de compreensão, em tese, deve ter como ponto de partida o repertório do leitor (os seus conhecimentos prévios). Kleiman (2000, p.13) chega a afirmar que "sem o engajamento do conhecimento prévio do leitor não haverá compreensão". Porém, vale lembrar que um dos objetivos da leitura é ampliar horizontes, portanto se deve apresentar aos leitores textos que ampliem a sua enciclopédia individual, por meio de propostas didáticas. A qualidade e a quantidade de conhecimentos do leitor contribuem na qualidade e na quantidade de informações que ele adquire via leitura. Assim, os textos destinados à leitura precisam extrapolar os conhecimentos de mundo da criança, para que seus níveis de compreensão também se ampliem (SOUSA, 2015, p. 81).

Fatores sociais e psicossociais, como a afetividade, também atingem o leitor, em aspectos como interesse e motivação para a leitura. Aspectos como a imagem que o leitor faz de si mesmo, as atitudes dos pares e dos adultos mais próximos são fatores que influenciam a leitura. A postura das pessoas mais próximas, que podem ser representadas por colegas, professores, pais em relação ao leitor, pode interferir na compreensão leitora. Sobre o tema, Sousa $(2015$, p. 107) ressalta o papel dos adultos e do professor para o engajamento do estudante com a leitura no sentido de que esses podem transformar a aula, construindo uma comunidade de leitores. O que esses mediadores externizam sobre o desempenho dos leitores reflete no progresso desses na compreensão textual, como ocorre em outras aprendizagens.

Sousa $(2015$, p . 107) propõe a análise da forma como as escolas vêm promovendo a leitura. As concepções dos professores podem interferir no modo como orientam o ensino da compreensão, já que passam por eles as iniciativas de estímulo. Estratégias para ajudar na superação de dificuldades são necessárias, pois, muitas vezes, o estudante sequer recebe incentivo dos familiares ou apresenta dificuldades para decifrar a escrita por não estar alfabetizado.

Um ambiente que crie situações estimuladoras de leitura, contribui no despertar de ânimo do estudante, pois ativa processos mentais que favorecem e intensificam a propensão à leitura. Viana et al. (2010, p. 5) destaca que, "as condições psicológicas, sociais e físicas do leitor afetam a compreensão do que é lido". Nesse sentido, a forma como o professor promove o seu trabalho afeta, mais positiva ou mais negativamente, tais condições, trazendo reflexos na compreensão textual.

Associando o exposto nos parágrafos anteriores com as dificuldades de leitura apresentadas pelos estudantes brasileiros nas avaliações nacionais e internacionais de leitura, reconhece-se a necessidade de se dar mais atenção ao fator contexto. É importante considerar como os professores lidam com os aspectos contextuais da leitura, por exemplo, como selecionam os textos. As características desses são aspectos relevantes para a motivação para a leitura. Deve-se considerar ainda o caráter polissêmico da leitura, a possibilidade de um mesmo texto ser interpretado de maneiras distintas, a depender de uma série de fatores, e não se tratando de qualquer interpretação. Conforme Marcuschi (2008, p. 256-257), "um texto permite várias leituras, mas não infinitas, pois a compreensão não é uma atividade de precisão, mas isso não quer dizer que ela seja imprecisa ou de adivinhação".

Assim, os leitores podem interpretar um texto de modos distintos, porém há uma margem de possibilidades coerentes para isso, e essas não podem ser desconsideradas. Nas palavras de Marcuschi (2008, p.257), "nossa compreensão não pode entrar em contradição com a verdade das proposições do texto: compreender é produzir modelos cognitivos compatíveis preservando o valor-verdade".

\section{Metodologia}

Para saber o que os professores pensam sobre sua prática pedagógica, foi elaborado e aplicado um questionário (aprovado pelo Comitê de Ética em 
Pesquisa em Seres Humanos - Parecer no 1.618.364) a 15 docentes (intitulados de P1 a P15) do 40 ano do Ensino Fundamental (EF), de 10 escolas de Curitiba (Paraná/ Brasil). Para abranger as distintas regiões da cidade, foram escolhidas unidades escolares de diferentes Núcleos Regionais de Educação, da Rede Municipal de Ensino da referida cidade. Esse instrumento trazia uma série de questões abertas, que objetivavam extrair do professor a sua forma de abordar a compreensão textual durante as aulas ministradas. Baseando-se nos dados, fez-se um esboço das percepções desses profissionais a respeito da compreensão leitora dos estudantes.

O questionário foi composto por quatro blocos de perguntas - formuladas conforme os fatores necessários à compreensão propostos por Viana et al. (2010): o texto, o leitor e o contexto, considerando as dimensões social, linguística e cognitiva da leitura, propostas por Spinillo (2013a)

Os questionamentos apresentados tinham como objetivo investigar se os docentes percebem dois aspectos. O primeiro é o fato de a leitura ser algo complexo, materializado na interação leitor-texto, e de que, na (re)construção de sentidos, o leitor aciona habilidades sociais, para situar-se no contexto do conhecimento prévio, das expectativas e propósitos de leitura; habilidades linguísticas, que exigem decodificação, vocabulário, conhecimentos de sintaxe e gêneros textuais; e habilidades cognitivas, que envolvem a memória, o monitoramento e as inferências (SPINILLO, 2013a). O segundo é que a complexidade da compreensão exige gerenciamento, o que a insere na esfera da metacognição, pois os processos de controle ajudam o leitor a assegurarse do alcance do objetivo proposto (VIANA et al., 2010). Parte-se do princípio, segundo o qual, o professor precisa se conscientizar de que há três tipos de fatores concorrendo para a leitura eficiente: os derivados do texto, como a estrutura e o conteúdo; os derivados do contexto, como a motivação; e os derivados do leitor, como as estruturas cognitivas e afetivas (VIANA et al., 2010).

A análise dos resultados foi feita considerando-se dados das respostas dos docentes. Essas foram organizadas em categorias e subcategorias, utilizando-se como base os próprios blocos em que foi subdivido o questionário: os textos como fatores que influenciam a compreensão; os fatores derivados do leitor e da sua importância na compreensão da leitura; os fatores derivados do contexto que afetam a compreensão leitora; e as estratégias de compreensão leitora.

Ressalte-se que a referida análise foi prioritariamente qualitativa. Em um primeiro momento, focalizou-se, separadamente, nas respostas de cada professor e, em um segundo momento, no conjunto das respostas dos docentes participantes.

\section{Resultados: análise e discussão}

Os apontamentos feitos pelos 15 professores que responderam ao questionário despertam para uma série de reflexões. Nas respostas dadas, emergem indicativos das concepções subjacentes às práticas de trabalho que adotam com a leitura e, consequentemente, com o ensino da compreensão textual.

As duas perguntas iniciais referiam-se a conhecimentos amplos que atingem o todo do trabalho de compreensão. A primeira questionava se, na opinião dos docentes, os fatores texto, leitor e contexto (Viana et al., 2010) teriam graus de importância distintos para a compreensão textual nos diferentes anos escolares e se algum deles seria mais importante, e, caso houvesse essa distinção, em que ano escolar isso aconteceria e por quê. A segunda, acompanhada por explicação sobre o que são competências simples e superiores, solicitava que descrevessem como e por que esses dois grupos de competências são relevantes.

As respostas dadas à primeira pergunta mostraram opiniões distintas. Em linhas gerais, oito professores apontam haver hierarquia, seis negaram essa hipótese e um não se explicitou opinião. Entre os que afirmaram haver graus de relevância, dois participantes citaram o $1^{\mathrm{O}}$ e o $2^{\mathrm{O}}$ ano, em conjunto, ressaltando o contexto como fator mais importante; dois apontaram o 4응 o 5 o ano, sem mencionar um fator; e um respondente afirma a supremacia do contexto em todos os anos escolares. Isso traz implicações para a qualidade do ensino da compreensão, pois, como justifica Schwarzbold (2011, p. 12), "quem domina a competência leitora é capaz de compreender o que leu, caso contrário, apenas decodificará o código escrito, já que compreender é estabelecer relações semânticas, ou melhor, é construir sentidos".

Quanto à segunda pergunta, novamente as opiniões se dividiram. Houve apontamentos sobre a interdependência entre as competências simples e superiores. Quatro respondentes têm a utilização de ambas como imprescindível à compreensão, fazendo-se presentes, inclusive, justificativas para tal importância. "A criança deve saber decodificar os símbolos, dando-lhes os sons adequados a cada sílaba e a compreender o que significa quando estão colocados em frases ou textos, visto que uma palavra pode apresentar significados diferentes"2.

As divergências de entendimento revelam a não afirmação de uma concepção de ensino para a compreensão. Isso reflete sobre o trabalho desenvolvido na alfabetização e, após a consolidação dessa, já que, considerando as diferentes necessidades de aprendizagem,

\footnotetext{
2 Trecho transcrito do questionário respondido pelo professor P1, no dia 08 de julho de 2016, em Curitiba/PR, Brasil.
} 
a escolha do processamento para o ensino da leitura repercute na eficácia da compreensão (se bottom-up ou ascendente, defende que a compreensão acontece da parte para o todo, privilegiando a decodificação, se top-down, ou descendente, defende que se dá do todo para as partes). "O sucesso do desempenho na compreensão da leitura está na escolha do processo mais eficiente para dar conta dessa situação, em que variáveis se inter-relacionam e influencia as decisões do leitor" (PEREIRA, 2015, p. 46).

Sobre essas duas primeiras perguntas, por envolverem questões intra e extratextuais, esclarece-se que ambas as competências são fundamentais e que o estudo em questão baseia-se em uma visão não dicotômica de leitura, propondo a compreensão como o resultado da articulação dos fatores texto, leitor e contexto, pressupondo que leitura requer compreensão, como recomenda Viana et al. (2010, p. 10). Assim, a concepção que melhor se ajusta é aquela que conjuga o ensino das duas competências, a partir dos dois modelos de processamento comentados. Ressalte-se que Coltheart (2013, p. 29) também defende a utilização conjunta desses modelos, o que chama de processamento de leitura misto ou de dupla rota.

Contudo, as especificidades de aprendizagem dos estudantes não podem ser negligenciadas. Acerca disso, Spinillo (2013b, p.139) afirma que as competências simples são mais importantes no início da escolaridade: "os efeitos da decodificação sobre o desempenho em leitura diminuem com o aumento da escolaridade, dando lugar para a atribuição de significados". Morais (2013, p. 77), corrobora esse pressuposto, sugerindo que não se deve trabalhar decodificação e compreensão ao mesmo tempo, por duas razões: a dificuldade de se "prestar atenção simultaneamente a duas atividades que são diferentes e implicam capacidades distintas" e a própria "dependência que existe entre decodificação e compreensão".

Especificamente sobre o fator texto, ao serem questionados se a adequação dos gêneros textuais ao ano escolar do estudante tem relevância para o ensino da compreensão e solicitados a explicar o porquê, seis professores disseram que sim; sete, que não; um disse não ter certeza e um não se expressou a respeito. Dentre os sins apresentados, um docente, embora tenha posto sim, pela justificativa, relativiza a resposta, como pode ser observado na transcrição abaixo. Note-se que, logo após dizer que "sim", especificou os gêneros apropriados para cada ciclo/ano.

Sim, acredito que podemos apresentar diversos gêneros textuais no processo de formação de escritores e leitores. [...] nas séries iniciais temos o cuidado de começar com textos que apresentam características mais conhecidas do universo infantil, como: listagem, músicas, [...]. Já, no segundo ciclo, devemos introduzir textos que exijam mais habilidades de interpretação, com questões explícitas e argumentativas, como: resenha, crônica, entre outros ${ }^{3}$.

Observa-se que, novamente, as opiniões se dividem. Como justificativas os professores que defenderam o "não" sustentaram-se em questões como a complexidade, a adequação à etapa e ao ensino, ao fato de nem todo gênero ter tema e linguagem apropriados à determinada ponto da escolaridade, como na resposta do docente P11: "Não, porque tem gêneros que não trazem tema e linguagem adequada que favoreça a compreensão $[. . .]^{4}$ ". Já as justificativas de quem defende o sim, em geral, pautam-se na relação do gênero textual e a ampliação do conhecimento, como se observa na resposta do docente P6: "Sim. Apresentar vários gêneros textuais amplia o

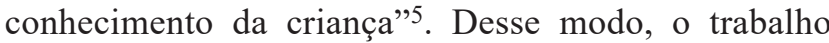
prioritário voltado ao ensino de gêneros secundários, evidencia-se como importante na ação docente, visto que de acordo com Silva e Souza (2016, p. 195) essa ação pode contribuir para "um salto qualitativo na maneira de pensar dos alunos". Não se deve perder de vista, é claro, as necessidades de aprendizagem, pois, como afirmam Pereira e Flôres (2012, p. 12), "a diversidade de gêneros e sequências deve estar presente no ensino da leitura, cabendo o estabelecimento de uma progressão com base na relação entre complexidade estrutural e nível de escolaridade".

Quanto à possibilidade de identificar e de inferir informações globais (macro) e locais (micro) nos textos, as opiniões foram variadas, defendendo-se posturas que vão desde trabalhar com tais informações a partir do $1^{0}$ ano até trabalhar com elas somente a partir do $5^{\circ}$ ano. Destaca-se a atenção dada pelos professores a aspectos como metodologia; conhecimento prévio; maturidade (idade); nível de alfabetização, entre outros, fatores relevantes no ensino, visto que: "A organização do texto e o conhecimento que o leitor possui sobre a. estrutura do mesmo interferem na compreensão, pois permitem discriminar a informação relevante da acessória e, também, a sua posterior evocação" (VIANA et al., 2010, p. 3-4).

Com relação à extensão do texto, utilizando como base para mensurar as referências estipuladas pelas pesquisadoras (arial 12, espaçamento 1,5, papel A4: aproximadamente 450 palavras, uma página; 225 , meia página; e 115 palavras, 1/4 de página), os professores consideraram que textos de, em média, 225 a 450 palavras apresentam extensão adequada para os estudantes de

\footnotetext{
3 Trecho transcrito do questionário respondido pelo professor P14, no dia 15 de setembro de 2016, em Curitiba/PR, Brasil.

4 Trecho transcrito do questionário respondido pelo professor $\mathrm{P} 11$, no dia 18 de agosto de 2016, em Curitiba/PR, Brasil.

5 Trecho transcrito do questionário respondido pelo professor P6, no dia 03 de agosto de 2016 em Curitiba/PR, Brasil.
} 
4 O ano. Não houve menção a textos de aproximadamente 115 palavras. As justificativas se firmaram em detalhes como a possibilidade de textos extensos tornarem a leitura cansativa. Ressalte-se que houve, inclusive, menção ao bom senso como forma de resolver a questão da extensão, o que se observa na resposta do P3 que, embora tenha apontado que a extensão adequada de um texto é de 450 palavras, argumenta: "Um texto pode ser mais longo e de fácil compreensão, depende da linguagem, do assunto, dos conhecimentos prévios, do contexto [...]"' . A resposta da professora aponta para a compreensão de que o nível de complexidade de um texto não está somente em sua extensão. Porém, observa-se preocupação com esse aspecto na literatura. Viana et al. (2010) demonstram isso, por exemplo, ao expor, em número de palavras, a extensão dos textos que trabalharam ao longo do seu estudo.

A legibilidade (tipo e corpo da letra, entrelinhamento, parágrafos etc.) é defendida como facilitadora da compreensão por 13 dos 15 professores, que se justificam em fatores de estímulo à leitura como a "aparência" e a organização dos textos que têm tamanho de fonte e espaçamento adequados. Já os indicadores tipográficos (títulos, subtítulos etc.) foram apontados como facilitadores da leitura, importantes para a antecipação e a orientação da compreensão. Viana et al. $(2010$, p. 4) ratificam essa ideia apontando que os aspectos editoriais presentes no texto facilitam a compreensão. Esses elementos ajudam o leitor a focar a sua atenção em informações importantes. Nessa vertente, Blank (2013, p.2), ao discorrer sobre as transformações pela qual passou a escrita, ressalta que a forma de lidar com a informação se transformou radicalmente, desse modo evidencia-se a necessidade de ensinar aspectos voltados à legibilidade e aos indicadores tipográficos, reafirmando a importância desses para a compreensão textual.

Quanto às ilustrações, todos os professores concordaram que favorecem a compreensão e tornam mais prazerosa a leitura, conforme os depoimentos a seguir. "Em textos infantis as ilustrações são muito importantes, pois além de facilitarem a compreensão divertem"7 e "Esses elementos auxiliam como referência no processo de construção da leitura [...]"8. Note-se que, no exposto pelo último respondente, são atribuídos a esses elementos dois enfoques: o potencial para serem ilustrativos e o potencial para serem esclarecedores. Vários autores (VIANA et al., 2010; RICHE, 2014) validam esse pressuposto. Sousa (2015) orienta que, em ambas as

\footnotetext{
6 Trecho transcrito do questionário respondido pelo professor $\mathrm{P} 3$, no dia 08 de julho de 2016, em Curitiba/PR, Brasil.

7 Trecho transcrito do questionário respondido pelo professor P3, no dia 08 de julho de 2016, em Curitiba/PR, Brasil.

8 Trecho transcrito do questionário respondido pelo professor P9, no dia 08 de agosto de 2016, em Curitiba/PR, Brasil.
}

situações, esses aspectos facilitam a leitura, sendo preciso oportunizar momentos de leitura cooperativa entre leitores menos e mais experientes, a fim de que esses possam auxiliar aqueles no estabelecimento de relações entre o texto verbal e o imagético.

Em se tratando dos fatores derivados do leitor e de sua importância na leitura, os professores, corroborando Viana (2010), ressaltaram que a linguagem oral interfere na compreensão, especialmente como promotora da ampliação do vocabulário, sendo o uso do dicionário a estratégia mais apontada.

Vale destacar que nenhum docente fez menção à morfologia. Contudo, os morfemas - raízes, afixos, desinências, entre outros aspectos - são unidades de significados e, portanto, exercem funções semânticas nos contextos das palavras. Nunes e Bryant (2014, p.119) afirmam que a estrutura morfológica ajuda as crianças a identificarem palavras que nunca ouviram antes, pelos morfemas conhecidos. Esse quadro indica que a morfologia é um assunto que precisa ser retomado.

Quanto à possibilidade de se apresentar textos para leitura cujo conteúdo não faça parte do repertório dos alunos, treze professores responderam afirmativamente e, mesmo um docente que apresentou apontamento contrário, pela justificativa deixa claro que é favorável a essa prática pedagógica: "Não [é possível]! Só podemos fazer isso com o devido encaminhamento metodológico anteriormente feito, devendo haver a preocupação em usar estratégias como pesquisa em grupos [...]"9. Viana et al. (2010) assumem essa conjectura em seu estudo, propondo um programa de atividades que atuam na Zona de Desenvolvimento Proximal dos Estudantes, ou seja, para além daquilo que eles conseguem fazer sozinhos.

Quanto aos encaminhamentos, esses apresentaram sugestões como a problematização para aguçar a curiosidade das crianças; a adaptação ao nível escolar do estudante; a antecipação da leitura, como se pode constatar nos trechos a seguir: "Com certeza é possível. Penso que sempre devemos apresentar textos que não façam parte do repertório dos estudantes, só assim ampliamos seu repertório[...]"10; "Sim. Desde que seja adaptado ao nível escolar do aluno"11; "É possível sim, pois se não conhecem determinado assunto passam a conhecer. Existem vários encaminhamentos para se abordar um texto com mensagem 'inédita' $[. .$.$] '12. Esse$ entendimento vai ao encontro do que defende autores,

\footnotetext{
9 Trecho transcrito do questionário respondido pelo professor P7, no dia 05 de agosto de 2016, em Curitiba/PR, Brasil.

10 Trecho transcrito do questionário respondido pelo professor P2, no dia 08 de julho de 2016, em Curitiba/PR, Brasil.

${ }^{11}$ Trecho transcrito do questionário respondido pelo professor $\mathrm{P} 4$, no dia 03 de agosto de 2016, em Curitiba/PR, Brasil.

12 Trecho transcrito do questionário respondido pelo professor P8, no dia 06 de agosto de 2016, em Curitiba/PR, Brasil.
} 
como Sousa (2015), Spinillo (2013a), Viana et al. (2010) e Kleiman (2000).

Sobre questões relacionadas à memória na compreensão, após explicitar que há dois tipos de memória (de curto prazo ou memória de trabalho e memória de longo prazo), questionou-se qual o papel que cada uma delas desempenha no processo de compreensão. As respostas variaram. Há os que explicaram o significado dos dois tipos de memória, mencionando o papel que desempenham na compreensão: "São importantes porque auxiliam a criança no momento da leitura (memória de curto prazo) e a fazer relação com o conhecimento prévio (memória de longo prazo)"13. Há os que afirmaram não saber o significado dessas expressões, os que relacionam as memórias de curto e de longo prazo a questões de relevância de conteúdo dos textos para os alunos, bem como os que relacionam aos objetivos de leitura, como mostra o docente P12, ao afirmar: "Não tenho conhecimento"14, ou o P10, ao dizer: "[Memória de curto prazo] Memórias passageiras, muitas vezes sem importância e significado. [Memória de longo prazo] Guarda coisas que têm significado real para o aluno"15. Pelo exposto, constata-se que os docentes sabem pouco sobre esses pressupostos teóricos e científicos, revelando uma lacuna a ser preenchida, pois, com esse conhecimento, poderiam atuar de forma mais consciente em suas intervenções pedagógicas. Segundo Spinillo (2013a, 178), é a memória de curto prazo que possibilita a integração de novas informações às antigas, "habilitando o leitor a detectar inconsistências entre as proposições do texto, estabelecer inferências, monitorar sua compreensão e construir um modelo mental". Já a memória de longo prazo trata-se de "processo cognitivo com uma capacidade expressiva de armazenamento que retêm a informação por bastante tempo", permitindo que o leitor leve para a leitura seus conhecimentos linguísticos e de mundo (SPINILLO, 2013a, p. 178).

Com relação à autoestima, a totalidade dos professores defendeu que a percepção do estudante sobre a sua leitura afeta a compreensão, ressaltando-se que todos eles, mesmo quando não explicitamente, associam as dificuldades de leitura à baixa autoestima. Fato que leva ao desinteresse: "Alguns [alunos] se colocam com uma dificuldade que não têm. Acham que não vão entender e abandonam a leitura. Essa postura [...] atrapalha o desempenho"16. Essa ideia é enfatizada em quase todas as respostas, com a presença de palavras e expressões

\footnotetext{
13 Trecho transcrito do questionário respondido pelo professor P2, no dia 08 de julho de 2019, em Curitiba/PR, Brasil.

14 Trecho transcrito do questionário respondido pelo professor P12, no dia 22 de agosto de 2016, em Curitiba/PR, Brasil.

15 Trecho transcrito do questionário respondido pelo professor P10, no dia 12 de agosto de 2016, em Curitiba/PR, Brasil.

${ }_{16}$ Trecho transcrito do questionário respondido pelo professor P3, no dia 08 de julho de 2016, em Curitiba/PR, Brasil.
}

como: "falta de interesse", "perda do interesse", "se achar incompetente", entre outras declarações. Essa condição precisa de atenção especial no ensino, pois, como explicita Viana et al. (2010, p.6), "As condições típicas e psicológicas do leitor influenciam também o tipo de leitura que é feito". O estímulo foi a atitude mais apontada para superar essa dificuldade. "Interfere na autoestima do aluno que, quando recebe apoio de outras pessoas adquire confiança maior em si e em sua capacidade"17; "A motivação e o exemplo de casa ajudam muito"18.

Diante do exposto, pode-se afirmar que os professores estão cientes do quanto a baixa autoestima interfere no potencial interpretativo dos estudantes. A importância da estrutura afetiva do leitor é enfatizada por Viana et al. (2010, p.10), ao afirmar: "as percepções de autoeficácia que o sujeito possui, as quais podem levá-lo a arriscar ou inibir-se de ler e que dizem respeito a atitude geral face à leitura e aos interesses do leitor, afectando profundamente a compreensão". Nesse sentido, é preciso investir em ações que auxiliem os estudantes a superarem suas dificuldades.

Com relação ao fator contexto, os elementos mais citados foram o tema e o assunto como características que despertam o interesse para a leitura. Em doze respostas, aparece uma dessas palavras, ou as duas, como premissa da motivação para ler. Elas não aparecem, explicitamente, apenas nas respostas de 3 professores, como a do $\mathrm{P} 1$, que destacou as estratégias de intervenção: “[...] preparar estratégias para instigar a curiosidade do que irá ler ou ouvir" ${ }^{19}$. Nesse sentido, como o fator contexto se liga diretamente ao fator leitor, a adequação dos temas e assuntos contribui na motivação para a leitura. Spinillo (2013a, p. 173) corrobora essa ideia expondo que a "compreensão também é influenciada pela expectativa que o leitor tem sobre o texto enquanto entidade linguística".

Com relação à linguagem, a maioria dos docentes destacou que é preciso promover a leitura de textos cujo vocabulário e/ou tema não se limite ao repertório dos leitores, de modo a facilitar a ampliação vocabular dos estudantes e a aquisição de novos conhecimentos e habilidades de leitura, por meio de inferências espontâneas ou mesmo de intervenções para que isso ocorra. Houve professores que usaram a expressão "atuar na sua Zona de Desenvolvimento Proximal”. Morais, Leite e Kolinsky (2013) chegam a afirmar que "a leitura é o poderoso instrumento de ampliação do vocabulário" e Sousa (2015, p. 19-20) remete à aproximação entre letramento e leitura,

\footnotetext{
17 Trecho transcrito do questionário respondido pelo professor P10, no dia 12 de agosto de 2016, em Curitiba/PR, Brasil.

${ }^{18}$ Trecho transcrito do questionário respondido pelo professor $\mathrm{P} 4$, no dia 03 de agosto de 2016, em Curitiba/PR, Brasil.

19 Trecho transcrito do questionário respondido pelo professor P1, no dia 08 de julho de 2016, em Curitiba/PR, Brasil.
} 
ao expressar, que a literacia, ou seja, o letramento: "supõe as capacidades de lidar com o escrito, possibilitando que, a partir dos conhecimentos e reflexão construídos, se elabore uma melhor compreensão do mundo que nos rodeia, pondo-o em perspectiva e questionando-o".

Vista dessa forma, a compreensão torna-se um instrumento de aprendizagem e de exercício da cidadania. Quanto aos aspectos voltados para o texto como produção de sentido, a totalidade dos docentes concorda que os textos podem apresentar mais de um sentido, podendo o leitor interpretar um mesmo texto de diferentes maneiras. As justificativas centraram-se no âmbito de que os leitores têm diferentes experiências que se refletem em singularidades de visões de mundo, de conhecimentos prévios e de bagagem sociocultural. Além disso, chamase a atenção para um aspecto apresentado nas respostas dos professores que escapa desse raciocínio: o fato de os textos serem passíveis a mais de uma interpretação. Isso retoma a argumentação de Marcuschi (2008, p. 257), já discutida neste documento, que destaca que um texto permite várias interpretações, ressaltando que nem todas as interpretações são possíveis, não podendo a compreensão entrar em contradição com as proposições do texto.

Com relação às estratégias motivadoras da compreensão, os docentes defenderam os seus pontos de vista com foco no planejamento e na escolha do texto; nos encaminhamentos metodológicos e nas atividades desenvolvidas; nas diferenças individuais; na construção das condições para a leitura, reforçando-se a importância das estratégias de ensino para a construção de conhecimento, uma vez que elas têm potencial para criar desafios para que o estudante aprenda. Os professores defendem o monitoramento da leitura como aspecto relevante e, que a intervenção em prol dessa habilidade, deve ser feita via leitura, estímulo à pesquisa, reescrita em linguagem mais acessível, questionamentos, entre outras. Destaca-se, porém, que, conforme Perfetti, Landi e Oakhill (2013, p. 253), "a baixa compreensão parece estar associada a um baixo desempenho do monitoramento".

Quanto à relevância da habilidade de explorar o texto para formular antecipações ou suposições sobre o seu conteúdo, denota-se que, embora algumas respostas mostrem clareza acerca da relação memória e cognição, há indícios de que esse tema ainda precisa ser retomado. $\mathrm{O}$ docente $\mathrm{P} 14$, por exemplo, compreende práticas que estimulem a memória como atividades de memorização. Solé (1998) já argumentava que as estratégias usadas durante a leitura devem ajudar o estudante a utilizar o conhecimento prévio, para fazer inferências, tomar ciência de algo que não se tenha entendido no texto, com o objetivo de procurar elucidá-los. Spinillo (2013a) corrobora as questões relacionadas ao monitoramento da compreensão.

Dez professores assumem que nunca pensaram sobre a diferença existente entre as atividades de avaliação e as de ensino da compreensão leitora. Porém, como em nenhuma das respostas consta a ideia de ensino da compreensão por meio de atividades metacognitivas, é notório que esses conceitos podem não estar claros para muitos professores. Acerca desse último aspecto, Giasson (1993, p. 299-300) argumenta que avaliar e ensinar compreensão leitora envolvem circunstâncias diferentes, havendo perguntas próprias para o "produto", ou seja, para a avaliação da compreensão, e para o "processo", ou seja, o ensino dessa.

\section{Considerações finais}

O processo de ensino da compreensão deve acontecer a partir de intervenções pedagógicas que busquem uma interação entre as estruturas cognitiva e afetiva dos alunos. Respeitar esses aspectos e utilizar aparatos de ensino adequados, com métodos e materiais apropriados, são caminhos para que os alunos possam aprender realmente a compreender o que leem, devendo a metacognição perpassar pelas estratégias utilizadas. Nesse sentido, como afirma Sousa (2015, p. 105), "o ensino da leitura carece de ser explícito e sistemático, tendo em conta os textos (estrutura e mecanismos linguísticos), os contextos e as finalidades da leitura".

O conjunto das respostas dos professores apresenta, pelo menos, dois pontos que merecem atenção. O primeiro diz respeito aos conhecimentos que envolvem o ensino da compreensão leitora. Os referentes às dimensões social e linguística da leitura foram bastante apontados, já os referentes à dimensão cognitiva revelaram-se quase desconhecidos pelos professores. Quanto aos demais, os aspectos que não aparecem nos excertos de um docente, estão presentes nos de outros. O segundo ponto, em contrapartida, trata-se das divergências de opiniões, indicando necessidades de estudo para esclarecimento quanto a cada ponto que envolve a compreensão da leitura.

O exposto dá indícios da importância da formação continuada, pois ela é a oportunidade para se suprir e ajustar conhecimentos às práticas pedagógicas. Nessa perspectiva, promover momentos em que os docentes possam estar juntos para elaborarem seus planejamentos e estudarem, por exemplo, pode oportunizar a troca de experiências, a reflexão, a discussão e a proposição de novas práticas. Com isso, eles próprios poderiam avançar na ressignificação e na transformação de suas práticas de docência no que se refere à compreensão da leitura. 


\section{Referências}

ALÉGRIA, Jésus; LEYBAERT Jacqueline; MOUSTY, Phillipe. Aquisição da leitura e distúrbios associados: avaliação, tratamento e teoria. In: GRÉGOIRE, Jacques; PIÉRART, Bernadette (org.). Avaliação dos problemas de leitura: os novos modelos teóricos e suas implicações diagnósticas. Porto Alegre: Artes Médicas, 1997. p. 105-124.

BLANK, Soraia Cristina. A influência da organização textual na compreensão leitora. Pensares em Revista, São Gonçalo, n. 2, p. 58-68, jan./jun. 2013. Disponível em: http:// www.e-publicacoes.uerj.br/index.php/pensaresemrevista/ article/view/7603/5482. Acesso em: 10/03/ 2017. https://doi. org/10.12957/pr.2013.7603

COLTHEART, Max. Modelando a leitura: a abordagem da dupla rota. In: SLOWLING, Margaret J.; HULME, Charles. A ciência da leitura. Porto Alegre: Penso, 2013. p. 24-41.

GIASSOM, Jocelyne. A compreensão na leitura. Lisboa: Asa Edições, 1993.

\section{INSTITUTO PAULO MONTENEGRO; AÇÃO} EDUCATIVA. Indicador de Alfabetismo Funcional - INAF: estudo especial sobre alfabetismo e mundo do trabalho. São Paulo: IPM, 2016. Disponível em: http://acaoeducativa.org.br/ wp-content/uploads/2016/09/INAFEstudosEspeciais_2016_ Letramento_e_Mundo_do_Trabalho.pdf. Acesso em: 15 out. 2018.

KLEIMAN, Angela. Texto e leitor: aspectos cognitivos da leitura. 7. ed. Campinas: Pontes, 2000.

MARCUSCHI, Luiz. Antônio. Produção textual e análise de gêneros e compreensão. São Paulo: Parábola Editorial, 2008.

MORAIS, José. Criar leitores: para professores e educadores. Barueri: Manole, 2013.

MORAIS, Jose; LEITE, Isabel; KOLINSKY, Régine. Entre a pré-leitura e a leitura hábil: condições e patamares da aprendizagem. In: MALUF, Maria Regina; CARDOSOMARTINS, Cláudia (org.). Alfabetização no século XXI: como se aprende a ler e a escrever. Porto Alegre: Penso, 2013. p. 138-154.

NAGY, William E.; SCOTT, Judith A. Vocabulary processes. In: KAMIL, M. et al. (ed.). Handbook of reading research. Mahwah: Lawrence Erlbaum Associates, 2000. v. 3, p. 269-284.

NUNES, Terezinha Nunes; BRYANT, Peter. Leitura e ortografia: além dos primeiros passos. Porto Alegre: Penso, 2014.

OAKHILL, Jane; CAIN, Kate; ELBRO, Carsten.

Compreensão da leitura: teoria e prática. Tradução Adail Sobral. São Paulo: Hogrefe CETEPP, 2017.
PEREIRA, Vera Wannmacher. A compreensão leitora no ensino fundamental: situação, apoio teórico e encaminhamento pedagógico. Revista de Estudos Legislativos, Porto Alegre, ano 9, n. 9, p. 39-56, 2015. Disponível em: http://submissoes.al.rs.gov.br/index.php/estudos_legislativos/ article/download/182/pdf. Acesso em: 10 out. 2018.

PEREIRA, Vera Wannmacher; FLÔRES, Onici Claro. Ensino da leitura: compreensão e traços linguísticos do texto. In: SIMPÓSIO INTERNACIONAL DE ENSINO DE LÍNGUA PORTUGUESA, 2., 2012, Uberlândia. Anais [...]. Uberlândia: EDUFU, 2012. v. 2, p. 1-10. Disponível em: http://www.ileel. ufu.br/anaisdosielp/wp-content/uploads/2014/07/volume_2_ artigo_300.pdf. Acesso em: 14 out. 2018.

PERFETTI, Charles A.; LANDI, Nicole; OAKHIL Jane. A aquisição da habilidade de compreensão da Leitura. In: SLOWLING, Margaret J.; HULME, Charles. A ciência da leitura. Porto Alegre: Penso, 2013. p. 245-265.

PINHEIRO, Ângela Maria V. Frequency of occurrence of words in textbooks exposed to Brazilian children in the early years of elementary school. [S. l.: s. n.], 2015.

RICHE, Rosa Maria Cuba. Texto e ilustrações: a produção de sentidos na leitura. In: SIMPÓSIO EDUCAÇÃ̃O E SOCIEDADE CONTEMPORÂNEA: DESAFIOS E PROPOSTAS - A ESCOLA E SEUS SENTIDOS, 9., 2014, Rio de Janeiro. Anais [...]. Rio de Janeiro: Universidade do Estado do Rio de Janeiro, 2014. Disponível em: http://www. cap.uerj.br/site/images/trabalhos_espacos_de_dialogos/34Riche.pdf. Acesso em: 23 out. 2018.

SCHWARZBOLD, Caroline. Desenvolver a competência leitora: desafio do professor do ensino fundamental. 2012. Trabalho de Conclusão de Curso (Especialização em Linguística Aplicada) - Programa de Pós-Graduação em Linguística Aplicada, Faculdade de Letras, Universidade Federal de Pelotas, Pelotas, 2011. Disponível em: https:// wp.ufpel.edu.br/letras-pos/especializacao/files/2012/02/ Desenvolver-a-compet\%C3\%AAncia-leitora-desafio-aoprofessor.pdf. Acesso em: 12 jun. 2019.

SILVA, Joice Ribeiro Machado da; SOUZA, Renata Junqueira de. O ensino das estratégias de compreensão leitora: uma proposta com livros de literatura infantil. Nuances: Estudos sobre Educação, Presidente Prudente, v. 27, n. 2, p. 192-205, mai./ago. 2016. Disponível em: https://repositorio.unesp.br/ handle/11449/108629. Acesso em: 11 out. 2019. https://doi. org/10.14572/nuances.v27i2.3783

SOARES, Adriana Benevides; EMMERICK, Thamires de Abreu. Compreensão de textos: processos e modelos. In: MOTA, Marcia Maria Peruzzi Elia da; SPINILLO, Alina. Compreensão de textos: processos e modelos. São Paulo: Casa do Psicólogo, 2013.

SOLÉ, Isabel. Estratégias de leitura. 6. ed. Porto Alegre: Artmed, 1998.

SOUSA, Luciene Bender de; GABRIEL, Rosângela. Aprendendo palavras através da leitura. Revista Linguagem 
\& Ensino, Santa Cruz do Sul, v. 16, n. 1, jan./jun. 2013.

Disponível em: http://www.rle.ucpel.tche.br/index.php/rle/ article/view/793/0. Acesso em: 12 out. 2018.

SOUSA, Otília Costa e. Textos e contextos: leitura, escrita e cultura letrada. Porto: Formalpress, 2015.

SPINILLO, Alina Gaçvão. A dimensão social, linguística e cognitiva da compreensão de textos: considerações teóricas e aplicadas. In: MOTA, Márcia Pieruzzi E. da; SPINILLO, Alina Galvão (org.). Compreensão de textos. São Paulo: Casa do Psicólogo, 2013a. p. 171-198.

SPINILLO. Alina Galvão. Alfabetização e consciência metalinguística: da leitura da palavra a leitura do texto. In: MALUF, Maria Regina; CARDOSO-MARTINS, Cláudia. (org.). Alfabetização no Século XXI: como se aprende a ler e a escrever. Porto Alegre: Penso, 2013b. p. 138-154.

VIANA, Fernanda Leopoldina et al. O ensino da compreensão leitora: da teoria à prática pedagógica: um programa de intervenção para o 1을iclo do Ensino Básico. Coimbra: Edições Almedina, 2010.

Recebido em: $15 / 11 / 2018$

Aprovado em: 29/5/2019.

Publicado em: 5/11/2019.

\section{Autoras:}

Terezinha das GraÇAS Laguardia Oliveira

Mestre em Educação, Universidade Federal do Paraná. Doutoranda em Educação, Programa de Pós-Graduação em Educação da Universidade Federal do Paraná (UFPR), Curitiba, PR, Brasil.

Orcid: http://orcid.org/0000-0002-3733-1749

E-mail: tere.laguardia@ufpr.br

Magaly Quintana Pouzo Minatel

Mestre em Educação, Universidade Federal do Paraná. Doutoranda em Educação, Programa de Pós-Graduação em Educação da Universidade Federal do Paraná (UFPR), Curitiba, PR, Brasil.

Orcid: http://orcid.org/0000-0002-3815-9282

E-mail: magalyminatel@ufpr.br

SANDRA REgina KiRCHNER GUIMARÃES

Doutora em Psicologia Escolar e do Desenvolvimento Humano,

Universidade de São Paulo (USP). Professora Permanente do

Programa de Pós-Graduação em Educação da Universidade Federal

do Paraná (UFPR), Curitiba, PR, Brasil.

Orcid: http://orcid.org/0000-0003-3441-0983

E-mail: srkguimaraes@ufpr.br

Endereço: Rua XV de Novembro, 1299

80060-000, Curitiba, PR, Brasi 